\title{
Design Sensibilities - Designing for Cultural Sensitivity
}

\author{
Jonna Häkkilä \\ University of Lapland \\ Finland \\ jonna.hakkila@ulapland.fi \\ Tapio Seppänen \\ University of Oulu \\ Finland \\ tapio.seppanen@oulu.fi
}

\author{
Mikael Wiberg \\ Umea University \\ Sweden \\ mwiberg@informatik.umu.se
}

\author{
Ilkka Juuso \\ University of Oulu \\ Finland \\ ilkka.juuso@oulu.fi \\ Katrin Wolf \\ Beuth University of Applied Sciences, \\ Berlin \\ Germany \\ Katrin.Wolf@beuth-hochschule.d
}

\author{
Nils Johan Eira \\ Sámi Archives, National Archives of \\ Norway \\ Norway \\ nileir@arkivverket.no
}

\author{
Maija Mäkikalli \\ University of Lapland \\ Finland \\ maija.makikalli@ulapland.fi
}

\begin{abstract}
When designing interactive systems and applications, we need to take into account different user groups, contexts, and cultural sensitivities. The challenges in culturally sensitive design can arise e.g. from historical, ideological, or ethical factors, and need to be considered when conducting HCI research, e.g. with cultural heritage, under-represented user groups, topics of cultural rituals, or in cross-cultural interfaces. The digitalizing world crosses old borders by bringing technology connectivity for new domains, and provides the means to distribute information that has previously been harder to access, and which may contain strong cultural meanings. With emerging technology use, new etiquette and social practices are formed to reflect the new sub-cultures. This workshop addresses the cultural sensitivities when designing interactive systems. The workshop invites researchers and practitioners to present and discuss about related case studies, applications, research methods, and experiences.
\end{abstract}

\section{CCS CONCEPTS}

- Human-centered computing $\rightarrow$ Empirical studies in collaborative and social computing.

\section{KEYWORDS}

culturally sensitive design, cultural heritage, ethics, conflict resolution, cross-cultural design

ACM Reference Format:

Jonna Häkkilä, Mikael Wiberg, Nils Johan Eira, Tapio Seppänen, Ilkka Juuso, Maija Mäkikalli, and Katrin Wolf. 2020. Design Sensibilities - Designing for

Permission to make digital or hard copies of part or all of this work for personal or classroom use is granted without fee provided that copies are not made or distributed for profit or commercial advantage and that copies bear this notice and the full citation on the first page. Copyrights for third-party components of this work must be honored

For all other uses, contact the owner/author(s).

NordiCHI '20, October 25-29, 2020, Tallinn, Estonia

(C) 2020 Copyright held by the owner/author(s).

ACM ISBN xxx-x-xxxx-xxxx-x

https://doi.org/10.1145/Xxxxxxx.Xxxxxxx
Cultural Sensitivity. In Proceedings of the 11th Nordic Conference on HumanComputer Interaction: Shaping Experiences, Shaping Society (NordiCHI '20), October 25-29, 2020, Tallinn, Estonia. ACM, New York, NY, USA, 3 pages. https://doi.org/10.1145/3419249.3420100

\section{INTRODUCTION}

In the globalizing world, we are still influenced by our cultural heritage, and also new subcultures are arising. While global digital services and consumer products often seek a universal design approach, cultural differences still play a role in what is preferred, expected, or accepted, from the design of interactive systems. Internet and social media are bringing challenges related to digital content spreading and being consumed worldwide, regardless of its origin and cultural context. Technology adoption and use can be influenced by social acceptability, online etiquette, and perceived privacy, which have cultural dependencies. Cultural sensitivities can arise from different viewpoints, such as historical, ideological, or have other more specific roots. In the era of globalization and digitalization, it is increasingly important to understand the sensitivities that can occur.

\section{RELATED WORK}

Cultural sensitivity is a well-known phenomenon, which has gained researchers' intensive attention across different fields. The six cultural dimensions identified by Hofstede, namely Power Distance, Uncertainty Avoidance, Individualism versus Collectivism, Masculinity versus Femininity, Long Term versus Short Term Orientation, and Indulgence versus Restrain [7], have become the paradigm in the area, and have influenced researchers and practitioners for decades (see e.g. [12]). Hofstede's cultural dimensions have been extensively applied to research seeking to understand user behaviour and preferences in different cultural contexts. In the area of human-computer interaction, cultural sensitivity is a relevant matter from several viewpoints, which both researchers and practitioners need to take that into account when considering, e.g., social acceptability, the 
generalizability of an application or service concept across different contexts, or the understandability of user interface visualizations.

Designers and researchers working on interactive systems come across cultural factors that impact different phases of the technology design process, and further to its adoption and use. For example, intercultural differences on privacy sensitivity, impact on both technology design, and how it is adopted by large audiences. User interface designers need to be aware of cultural sensitivities already when carrying out the practical concept design tasks and making choices on the interaction design and graphics. Awareness of how colors, symbols, or certain objects are perceived across different cultures is an important factor that should be taken into account in design [9]. It can easily happen that a symbol or graphics that is designed in one cultural context ignores the culturally sensitive meaning it carries in another context.

Correll has addressed the ethics of information visualization, and discusses, e.g., how historical war statistics can be presented to reflect the human tragedy [2]. The context of death and mourning is acknowledged to be a sensitive topic for design, influenced both by individual grieving and cultural traditions and rituals. This is highlighted in HCI research exploring design for deathscapes [5, 6] and memorial presentations such as gravestones [4]. With the rituals of remembrance and death, the aesthetic and atmosphere inherent in the design is important. This is demonstrated in the Thanato Fenestra concept, where candle light is used as a trigger for a photo memorial of a past family member [13]. Cross-cultural design can be additionally challenging within contexts that have ideological tension. Topics, or geographical locations, that are prone to political and ideological tension are challenging design contexts (e.g. [1, 15]). In such circumstances inconsiderate designs may easily lead to misunderstandings, or even be perceived as a provocation.

Cultural heritage is a large area where cultural sensitivity needs to be taken into account, and where new challenges appear with digital technologies. For instance, on one hand, digital technologies can offer access to historical sites which would be hard to enter or are prone to damage if visited [16]. On the other hand, exposing these sites can be perceived as an intrusion, e.g., if the site is considered as sacred, or carries a strong cultural or religious meaning. This can be the case for instance with historical tombs or sites of worship. Similar challenges can be seen with historical and archived materials, which can suddenly become available through content digitization, 3D modeling, the creation of digital archives, virtual museum exhibitions. For instance, indigenous cultural heritage can include records that are perceived as very private or sacred, or their rarity is associated with assimilation policies and the historical collections are linked with the history of colonization [3]. The ways of presenting and communicating sensitive heritage are relevant to consider both in communication, exhibition design, and in the visual design language. Also games and design fictions that are depicted in a historical context must face the cultural challenge and consider, e.g., the balance between maintaining historical authenticity and creating an engaging narrative or characters [8].

In addition, the digital world has created new sub-cultures, which have developed together with emerging technologies and practices. The online era has given birth to different cybercultures, which are associated with online social spaces and the digitally networked culture [10]. These cultures can have their own unspoken rules and norms for accepted, or desired, behavior. For instance, it has been shown that social media etiquette requirements are influenced by age and social media expertise [14]. Moreover, different media channels follow different etiquette [14]. Thus, it is important to understand human behavior and sensitivities also in emerging digital cultures. Novel technologies, such as wearable computing and virtual reality headsets, will require culture sensitive design e.g. related to the social acceptance of the technology use [11].

\section{THE WORKSHOP AREAS OF INTEREST}

The aim of the workshop is to gather together researchers, designers and practitioners that are working with culturally sensitive topics. The workshop aims to be a forum to present different viewpoints, challenges and lessons learned, and offer a stage where these questions can be discussed with peers and new colleagues with similar interests. We encourage multi-disciplinary participation, and wish to provide an opportunity to network. The workshop works towards recognizing the culturally sensitive contexts, topics and issues, and distributing knowledge on best practices and experiences to prevent conflicts when designing for culturally sensitive topics.

The workshop invites researchers and practitioners with background in, but not limited to, HCI, design, memory organizations, cultural studies, and indigenous cultural heritage. The workshop invites submissions of case studies, applications, methodological notes, as well as position papers, related to $\mathrm{HCI}$ and design for topics such as

- indigenous communities

- under-represented cultural groups and emerging subcultures

- culturally sensitive heritage, sacred sites, and religion

- using historical artifacts, contexts and materials for design

- death, remembrance, and rituals

- political and ideological tension

- cross-cultural contexts, and differences in symbolism, semantics, and UI design

- ethics, participatory, and cross-generation approaches to cultural sensitivity

- cybercultures and online etiquette

\section{ORGANIZERS}

Jonna Häkkilä is professor at University of Lapland, Finland, Faculty of Art and Design. She conducts research on various aspects of user centric design, and has interests on designing with cultural heritage, death and mourning. Currently, she leads an Interreg Nord research project Digital Access to Sámi Heritage Archives.

Mikael Wiberg is a full professor in informatics at Umea University, Sweden. Wiberg's main work is within the areas of interactivity, mobility, materiality, and architecture. He is a co-editor in chief of ACM Interactions, and his most recently published book is The Materiality of Interaction: Notes on the Materials of Interaction Design (2018).

Nils Johan Eira works in The National Archives of Norway, Sámi archives department. He has a master degree in indigenous journalism at the Sámi University of Applied Science. He is a Sámi, 
has worked as a reindeer herder, television, news journalist, and for Sámi youths for Norwegian Broadcasting Corporation, NRK Sápmi.

Tapio Seppänen is a professor at the University of Oulu, Finland, in the Faculty of Information Technology and Electrical Engineering. He has a long background in information technologies such as digital humanities, multimedia data analysis, machine learning and biomedical engineering.

Ilkka Juuso is a post doctoral researcher in computer science at University of Oulu, and has an extensive background in crossdisciplinary research projects involving the use of large-scale cultural heritage materials from, e.g., the Linguistic Atlas Project (LAP) in the USA and the Historical Thesaurus of the Oxford English Dictionary (HTOED) in Europe.

Maija Mäkikalli is a lecturer for art and culture history at University of Lapland. Her research interests include how archives and museum face the challenges and opportunities when combining historical content and the digital era.

Katrin Wolf is a professor for Human-Computer Interaction at Beuth University of Applied Sciences, Berlin, and conducts research on the user-centric design of new technologies, including AR/MR/VR, smart objects, and haptic interfaces.

\section{ACKNOWLEDGMENTS}

This work has received support from the Interreg Nord project Digital Access to Sámi Heritage Archives.

\section{REFERENCES}

[1] Javier Borge-Holthoefer, Walid Magdy, Kareem Darwish, and Ingmar Weber. 2015. Content and network dynamics behind Egyptian political polarization on Twitter. In Proceedings of the 18th ACM Conference on Computer Supported Cooperative Work \& Social Computing. 700-711.

[2] Michael Correll. 2019. Ethical dimensions of visualization research. In Proceedings of the 2019 CHI Conference on Human Factors in Computing Systems. ACM, 188.

[3] Thomas Hylland Eriksen, Sanna Valkonen, and Jarno Valkonen. 2018. Knowing from the Indigenous North: Sámi Approaches to History, Politics and Belonging. Routledge.

[4] Jonna Häkkilä, Ashley Colley, and Matilda Kalving. 2019. Designing an interactive gravestone display. In Proceedings of the 8th ACM International Symposium on Pervasive Displays. 1-7.

[5] Jonna Häkkilä, Meri-Tuulia Forsman, and Ashley Colley. 2018. Navigating the graveyard: designing technology for deathscapes. In Proceedings of the 17th International Conference on Mobile and Ubiquitous Multimedia. 199-204.

[6] Jonna Häkkilä, Petri Hannula, Elina Luiro, Emilia Launne, Sanni Mustonen, Ton Westerlund, and Ashley Colley. 2019. Visiting a virtual graveyard: designing virtual reality cultural heritage experiences. In Proceedings of the 18th International Conference on Mobile and Ubiquitous Multimedia. 1-4.

[7] Geert Hofstede. 2011. Dimensionalizing cultures: The Hofstede model in context. Online readings in psychology and culture 2, 1 (2011), 8.

[8] Elina Luiro, Petri Hannula, Emilia Launne, Sanni Mustonen, Toni Westerlund, and Jonna Häkkilä. 2019. Exploring local history and cultural heritage through a mobile game. In Proceedings of the 18th International Conference on Mobile and Ubiquitous Multimedia. $1-4$.

[9] Aaron Marcus and Emilie W Gould. 2000. Cultural dimensions and global web user-interface design: What? So what? Now what. In Proceedings of the 6th Conference on Human Factors and the Web, Vol. 19.

[10] Pramod K Nayar. 2010. An introduction to new media and cybercultures. John Wiley \& Sons.

[11] Valentin Schwind, Jens Reinhardt, Rufat Rzayev, Niels Henze, and Katrin Wolf 2018. Virtual reality on the go? a study on social acceptance of VR glasses. In Proceedings of the 20th International Conference on Human-Computer Interaction with Mobile Devices and Services Adjunct. 111-118.

[12] Mikael Søndergaard. 1994. Research note: Hofstede's consequences: a study of reviews, citations and replications. Organization studies 15, 3 (1994), 447-456.

[13] Daisuke Uriu and Naohito Okude. 2010. ThanatoFenestra: photographic family altar supporting a ritual to pray for the deceased. In Proceedings of the 8th ACM Conference on Designing Interactive Systems. ACM, 422-425.
[14] André Calero Valdez, Anne Kathrin Schaar, and Martina Ziefle. 2013. Personality influences on etiquette requirements for social media in the work context. In International Conference on Human Factors in Computing and Informatics. Springer, 427-446.

[15] Volker Wulf, Konstantin Aal, Ibrahim Abu Kteish, Meryem Atam, Kai Schubert, Markus Rohde, George P Yerousis, and David Randall. 2013. Fighting against the wall: social media use by political activists in a Palestinian village. In Proceedings of the SIGCHI Conference on Human Factors in Computing Systems. 1979-1988.

[16] AM Yasser, Kathy Clawson, and Chris Bowerman. 2017. Saving cultural heritage with digital make-believe: machine learning and digital techniques to the rescue. In Proceedings of the 31st British Computer Society Human Computer Interaction Conference. BCS Learning \& Development Ltd., 97. 